\title{
Monumentos del centenario en México y Argentina
}

\section{César González}

Este trabajo analiza la función simbólica de los monumentos que conmemoran las gestas de la Independencia en México y Argentina, a partir del estudio del concepto moderno de monumento histórico que se desarrolló sobre todo en el siglo XIX, con el auge y crecimiento de las ciudades y las rápidas transformaciones en el tejido urbano tradicional, pero especialmente con la formación de los estados nacionales y su necesidad de símbolos. Sobre todo se trata de explorar la relación entre memoria y monumento, sus implicaciones políticas y la construcción de un discurso tanto de los monumentos intencionales, hechos ex profeso, como de los monumentos no intencionales, significados por una colectividad.

Palabras Clave: monumento, símbolo, México, Argentina, discurso.

This paper analyzes the symbolic function of monuments commemorating the Independence in Mexico and Argentina, from the study of the modern concept of historical monument that was developed especially in the nineteenth century, with the rise and growth of cities and rapid changes in the traditional urban life, but especially with the formation of nation states and their need for symbols. Mostly it is about exploring the relationship between memory and monuments, its political implications and the construction of a discourse of intentional monuments, made expressly, as well unitentional monuments of meanings by a collectivity.

KEYWORDS: monument, symbol, Mexico, Argentina, speech.

Fecha de recepción: 22 de octubre de 2013

Fecha de aceptación: 7 de enero de 2014 

César González

Universidad Nacional Autónoma de México

Instituto de Investigaciones Filológicas

\section{Monumentos del centenario en México y Argentina}

El término "monumento", que no es muy antiguo en su concepción actual pues se dice que se usó por primera vez en la expresión monument historique en ocasión de la demolición de la Bastilla, está relacionado con la noción de memoria; proviene del latín monumentum y éste de monere, que remite a recordar, advertir, hacer saber, instruir. Tanto el término latino como los griegos mnema-mnemeion están vinculados a la raíz indoeuropea men, que expresa una de las funciones fundamentales de la mente (mens), la memoria (memini); por su parte, el sufijo -mentum puede indicar tanto una acción o un proceso como el resultado de la acción o el proceso.

Desde la antigüedad romana hay monumentos, aunque su sentido no era el mismo; según Le Goff, se pensaba el monumento como un signo del pasado y el término tenía dos sentidos: como obra de arquitectura o de escultura con fines conmemorativos, como arco de triunfo, columna, trofeo, pórtico, etc., y como monumento funerario. Este historiador, en su búsqueda histórica del término "memoria", dice que aparece muy temprano en las lenguas romances, en el vocabulario francés está ya desde el siglo XI; en el siglo xv, en la época de apogeo de las artes memoriae, aparece la palabra mémorable, y en el xvI, los escritos de personajes importantes se denominan mémoires; es la época cuando nace la historia y se afirma la noción de individuo. El pensamiento de 
la revolución francesa desarrolló la noción de monumento, pero la necesidad de conmemorar está en realidad más desarrollada entre conservadores y nacionalistas, para los cuales la memoria es un fin y un instrumento de gobierno. A partir de 1789 aparecen instrumentos nuevos de conmemoración, como monedas, medallas y estampillas, sobre todo en la segunda mitad del siglo XIX, además de las estatuas, inscripciones y lápidas conmemorativas (Le Goff, Jacques, El orden de la memoria, 227 y 153$)$.

El concepto moderno de monumento histórico se desarrolló sobre todo en el siglo XIX, con el auge y crecimiento de las ciudades y las rápidas transformaciones en el tejido urbano tradicional, pero especialmente con la formación de los estados nacionales y su necesidad de símbolos. El monumento histórico tiene la función de ser un recordatorio de acontecimientos o de personas, lo cual, a final de cuentas, remite a recordar el carácter efímero de la vida humana; es decir, su propósito fundamental no es proporcionar informaciones sino tratar con emociones.

La relación entre memoria y monumento ha sido acentuada desde los primeros escritos teóricos; por ejemplo, Aloïs Riegl dice en su tratado que, "en su más antiguo y original sentido, un monumento es una creación humana erigida para el propósito específico de conservar vivos las hechos y acontecimientos humanos en la mente de las generaciones futuras" (Le culte moderne des monuments...). Una primera distinción de Riegl es aquella entre los monumentos intencionales y los no intencionales; los primeros se construyen con el propósito de recordar un hecho o una persona, han existido desde que existe la cultura y pueden ser edificios o ciudades, los cuales son monumentos por su valor irreemplazable. Con esta distinción, extiende la denominación de monumento a cualquier artefacto que revele el paso del tiempo sin considerar su propósito o su sentido original; lo que lo define es la edad. En el caso del intencional, erigido para rememorar hechos o personas, su propósito es vencer la distancia temporal, rechazar el paso del tiempo; es un eslabón que une el pasado con el presente, que establece una conexión con lo que se quiere recordar. Su función es mantener vivo el recuerdo, detener el olvido. Por ello, la edad es un obstáculo y cualquier señal de deterioro disminuye su función, que es mantener vivo el interés por lo que en él se manifiesta. Sin embargo, el monumento no intencional, al 
no ser construido con el propósito de recordar, rechaza la transparencia y prefiere asumir la distancia en el tiempo. El valor del monumento intencional, continúa Riegl, está condicionado puesto que se conserva en tanto que la persona o el acontecimiento que con él se recuerda todavía importa para la sociedad; pero el valor del no intencional depende del observador ya que llamar monumento a un edificio es una designación subjetiva.

Desde los primeros años del siglo xx, época del libro de Riegl, la discusión acerca de la noción de monumento ha pasado a otras áreas; hoy se denomina de esa manera a una estructura ya sea que haya sido creado explícitamente para recordar una persona o un acontecimiento, ya sea que se haya convertido en algo importante para un grupo social como parte de sus recuerdos de hechos pasados. Ciertas estructuras funcionales - edificios públicos, casas, fábricas, estaciones de tren, etc.- que se destacan por su antigüedad, su tamaño o por su significado histórico, también pueden considerarse como monumentos. A menudo, los monumentos transportan cierta información histórica o política, pueden usarse para reforzar el poder político (como es el caso en muchos de los monumentos patrios), o para educar a la población acerca de hechos o personajes.

Los países latinoamericanos, a finales del siglo XIX y principios del $\mathrm{xx}$, encontraron una ocasión única de construir edificaciones, de erigir monumentos destinados a conmemorar los inicios de sus movimientos de independencia, los cuales surgieron en casi todas las capitales y ciudades importantes. Al ser el inicio de las luchas de independencia uno de los mayores acontecimientos en la historia de estos países, ese hecho no podía pasar inadvertido al cumplirse en 1910 el primer centenario. La llamada Columna de la Independencia en la capital mexicana y el proyecto del Monumento a Mayo en la capital argentina son dos de las edificaciones proyectadas para la conmemoración de este hecho. En México hubo un primer proyecto de monumento a la independencia ${ }^{1}$ en

${ }^{1}$ El "grito de Dolores" se considera como el momento de inicio de la guerra de independencia mexicana y es el llamado que el cura Miguel Hidalgo, junto con Ignacio Allende y Juan Aldama, hace a sus parroquianos para levantarse contra la autoridad virreinal de la Nueva España el 16 de septiembre de 1810. Este llamado se hace al tañer 
1843, cuando el presidente López de Santa Ana, después de convocar a un concurso, asignó el proyecto al arquitecto Lorenzo de la Hidalga. Este monumento debía estar en la Plaza de la Constitución y constaba de una gran columna flanqueada por fuentes, pero de ella sólo se terminó el basamento o zócalo, el cual bautizó a la plaza como Zócalo. Años más tarde, Maximiliano encarga al ingeniero Ramón Rodríguez otro proyecto de monumento, que tampoco se realiza. Durante los primeros años del gobierno de Porfirio Díaz, un concurso internacional para edificar un monumento para el centenario de la independencia, convocado en 1877, fue ganado por los arquitectos norteamericanos Cluss y Schultz, el cual tampoco se realizó pero sirvió de base para el diseño definitivo del arquitecto Antonio Rivas Mercado, quien lo tomó como modelo, además de algunas famosas columnas, desde las de Roma hasta las que erigidas en el siglo XIX en las principales ciudades europeas. Todas esas columnas fueron levantadas para conmemorar el triunfo de un ideal en sus respectivos países. La primera piedra del monumento a la independencia o columna de la independencia se colocó en 1902 y ocho años más tarde, el 16 de septiembre de 1910, se celebró la ceremonia de inauguración encabezada por el presidente Díaz. Los trabajos de cimentación se deben a los ingenieros Gonzalo Garita y Manuel Gorozpe. La columna, que mide 36 metros de alto, es hueca, de acero y recubierta con cantera labrada; en su interior hay una escalinata que asciende hasta la base del pedestal que soporta una estatua, conocida como el Ángel, aunque es realmente una victoria alada. En la parte inferior, la columna está rodeada de guirnaldas sujetas por cabezas de león y desde ellas ascienden ramas de laurel abrazadas por anillos labrados con los nombres de los héroes del movimiento insurgente; el capitel de la columna está formado con hojas de acanto, volutas y cuatro águilas. La victoria alada que remata el monumento mide 6.7 metros de altura y pesa siete toneladas, lleva una corona de laurel en una mano y un trozo de cadena, que simboliza la dominación española, en la otra. La escul-

\footnotetext{
la campana de Dolores, ubicada en la iglesia parroquial de Dolores (hoy Dolores Hidalgo), estado de Guanajuato. A partir de ese momento se inicia una guerra que culmina el 27 de septiembre de 1821, con la firma del Tratado de Córdoba, con el que se consuma la independencia de México.
} 
tura fue realizada por el escultor Enrique Alciati y está hecha de bronce y recubierta de oro.

El proyecto de monumento conmemorativo de la independencia argentina tiene un antecedente. En marzo de 1811, la Junta que sustituyó al derrocado virrey español, conocida como la Primera Junta, decide celebrar el 25 de mayo de ese año el primer aniversario de la Revolución de Mayo $^{2}$ por lo cual el Cabildo de la ciudad decide erigir un monumento y llamarlo Columna 25 de Mayo, con forma de obelisco, aunque desde los primeros años se le ha dado el nombre de pirámide. Éste fue el primer monumento patrio de Argentina. Dos meses después, el 25 de mayo de 1811, se inauguró la obra y de su construcción se encargó el alarife y maestro de obras Francisco Cañete. A mediados del siglo, hacia 1856, la pirámide estaba muy abandonada por lo que se encargó su transformación al pintor y arquitecto Prilidiano Pueyrredón, quien colocó en su parte superior una estatua de la libertad de $3.6 \mathrm{~m}$ de altura, coronada con un gorro frigio, estatua que fue realizada por el escultor francés Dubourdieu. El obelisco tiene una altura total de 19 metros. En 1907 se convocó a un concurso para el proyecto de un monumento, que se llamaría Monumento a Mayo, y sus resultados fueron expuestos en mayo de 1908; se presentaron setenta y cuatro proyectos, de los cuales sólo ocho eran locales, y los ganadores fueron los italianos L. Brizzolara, escultor, y G. Moretti, arquitecto. Múltiples dificultades de todo tipo, junto con las fuertes críticas al proceso total, entre ellas de Ricardo Rojas y de Leopoldo Lugones, impidieron que el proyecto se realizara. Entre otras cosas, las críticas iban en el sentido de la necesidad de demoler la pirámide; el resultado es que ésta se conservó y sólo fue trasladada al centro del nuevo trazado de la plaza en 1914 y que el monumento proyectado nunca se construyó.

${ }^{2}$ Se conoce como Revolución de Mayo la serie de hechos revolucionarios que se sucedieron en el mes de mayo de 1810 en la ciudad de Buenos Aires, entonces capital del Virreinato del Río de la Plata, dependencia colonial de España. Esos acontecimientos se centraron en la Semana de Mayo, entre el día 18, cuando se confirmó de manera oficial la caída de la Junta de Sevilla, y el 25, cuando el virrey Baltasar Hidalgo de Cisneros fue derrocado y remplazado por la Primera Junta. La Revolución de Mayo inició el proceso del cual surgió la nación argentina, aunque sin una proclamación formal de la independencia, pues la Primera Junta no reconocía la autoridad del Consejo de Regencia de España e Indias, que todavía gobernaba nominalmente en nombre del rey Fernando VII, aunque su lugar era ahora ocupado por el francés José Bonaparte. 
La forma elegida para ambos monumentos es la de columna, de sección circular en el caso de México y de sección cuadrada para el de Buenos Aires. En términos generales, una columna es una pieza arquitectónica que sirve normalmente para sostener el peso de una estructura, aunque también puede tener fines decorativos. Cuando la sección es circular, es propiamente una columna, pero cuando es cuadrangular se denomina pilar (o pilastra, si está adosada a un muro). La columna clásica está formada por tres elementos: basa, fuste y capitel. Un caso particular es el de la llamada columna conmemorativa, que no es pieza estructural de alguna construcción, sino que constituye en sí misma una edificación que sirve para recordar algún acontecimiento o algún personaje histórico. En este caso, sobre un podio generalmente elevado, se levanta un fuste de grandes dimensiones, que puede estar decorado con bandas de bajorrelieves que cubren su superficie; en el extremo superior, se alza una figura o una estatua. Los romanos la utilizaron para conmemorar acontecimientos de relieve nacional o para glorificar a sus emperadores. Son célebres la columna levantada en torno al año 113 a.C. en el Foro de Trajano, en Roma, para celebrar la conquista de Dacia, o la columna de Marco Aurelio erigida en el foro Antonino hacia 180 a.C. (hoy en la plaza Colonna de Roma) para conmemorar las victorias sobre los germanos. En épocas posteriores a la del imperio romano se ha seguido recurriendo a este tipo de monumento triunfal, del que son ejemplos la columna de la plaza Vendôme de París, de $44 \mathrm{~m}$ de alto con una estatua de Napoleón como remate para celebrar la victoria en Austerlitz; la columna en la plaza Trafalgar de Londres, terminada en 1843, con una altura de poco más de $50 \mathrm{~m}$ y con la estatua del almirante Nelson como remate, o la Columna de la Victoria de Berlín (Siegessäule), terminada en 1874, que tiene una altura de $69 \mathrm{~m}$ y remata con una estatua de la Victoria; finalmente, la columna dedicada al emperador Alejandro I en San Petersburgo, terminada en 1834 , de $47 \mathrm{~m}$ de altura y con la estatua del emperador que celebra la victoria sobre Napoleón.

Sería interesante pensar los monumentos, del centenario en particular, y todo el conjunto de monumentos y de hechos urbano-arquitectónicos en general, como un tipo de discurso de modo que fuera posible pensar la columna de la independencia de México y el proyecto de columna destinado a ocupar la que sería la Plaza de Mayo en Buenos Aires como 
discursos del centenario. Plantear las formas por medio de las cuales un pueblo recuerda los hechos, acontecimientos y personajes de su pasado en términos del concepto de discurso, supondría una doble labor: primero, un trabajo teórico que diera como resultado una definición, aun cuando fuera operativa, del concepto de discurso, y, segundo, la extensión de este concepto de manera que incluya no sólo la acepción tradicional de conjuntos de enunciados verbales sino también los formados por otras materias. Pensar el discurso como una entidad formada por signos verbales no constituye ningún avance pues es simplemente darle un nombre más a una noción existente (o, en los términos de Occam, es multiplicar los entes de manera innecesaria); con ello, además, se le quita al concepto de discurso su potencial teórico asociado a su carácter normativo y a su estatuto institucional, a los que me referiré enseguida.

Antes de abordar la cuestión de una definición de discurso, me referiré brevemente a la tipología de los discursos; estamos acostumbrados a expresiones del tipo "discurso político", "discurso literario", etc., lo cual asume que debe existir alguna manera de agrupar ciertos hechos en grupos como los mencionados; sin embargo, no podemos asumir esto sin discutirlo, o sea, sin buscar qué es lo que les da unidad o cuál es la base de su clasificación. Si se habla de discursos literarios es porque se asume que hay un grupo de textos, obras, etc., que pertenecen al conjunto que llamamos "literatura", que mantienen una cierta relación con un esquema discursivo preexistente que va más allá de las obras concretas e individuales y que, como esquema simbólico, es capaz de orientar tanto su producción como su lectura. ${ }^{3}$ A pesar de que los discursos literarios están construidos con enunciados lingüísticos, en ellos están presentes no sólo elementos de la lengua, por lo que su análisis no puede hacerse sólo pensando que son series de frases o de oraciones que remiten al código lingüístico; si así fuera, los textos literarios serían lineales o unidimensionales; es más, serían paradigmáticos en este

\footnotetext{
${ }^{3}$ No entraré aquí en la antigua discusión acerca de los rasgos del texto que bastan para calificarlo como literario. Baste decir que no se puede determinar su carácter literario sobre la base de características inherentes al texto; por tanto, que una obra pertenezca al conjunto de las consideradas como literarias sólo depende de ciertas normas aceptadas en una sociedad particular. Es decir, que lo que unifica un conjunto de textos es una entidad más amplia llamada "literatura" es su uso, su función en la vida social.
} 
sentido. Como todo texto cultural, no están determinados unívocamente sino que son objetos heterogéneos, susceptibles de producir múltiples sentidos, lecturas diversas. Este potencial de significación representa un peligro para las sociedades, por lo cual toda producción debe ser "controlada, seleccionada y redistribuida por un cierto número de procedimientos que tienen por función conjurar los poderes y peligros, dominar el acontecimiento aleatorio y esquivar su pesada y temible materialidad" (Foucault, Michel, El orden del discurso, 11). Por medio de tales procedimientos se introduce una normatividad que privilegia una lectura y sitúa las otras posibles en un segundo plano. Es decir, convierte las obras literarias en discursos, las reduce a ser manifestación del esquema discursivo que domina una determinada época en la vida de esa sociedad. En cada campo particular de la vida social existe un sistema que regula ese dominio y que produce el conjunto de discursos acerca de él; ese conjunto de reglas es parte de una institución, que en el campo de la literatura está formada por las revistas literarias, críticos, suplementos culturales, antologías, historias de la literatura, editoriales, profesores, investigadores y estudiantes de letras, congresos, sistemas de premios, etc. Los sociólogos ven la institución como un conjunto de normas que se aplican a un dominio particular de actividades y definen una cierta legitimidad. Funcionalmente, son modos de organización que aseguran la permanencia de los miembros de una colectividad dada y los integran en ella; su eficacia se logra por imponer sistemas de normas y valores cuyo vehículo son precisamente los discursos, que se caracterizan por presentar su objeto - en este caso los literarios - en términos de esencia, sin contactos con lo social o con la historia.

A esta altura de la exposición, debe ser evidente que podemos hablar de discurso no sólo para el caso de producciones que tienen una base material linguística sino para cualquier otra, como el caso de las edificaciones arquitectónicas que llamamos monumentos. Como ya se señaló, éstos se consolidan en la segunda mitad del siglo XIX con las transformaciones urbanas y la necesidad de símbolos para los recientes estados nacionales. El momento fundador de una institución es cuando aparece una legitimidad que se elabora internamente y, con ella, esas prácticas se vuelven autónomas y distintivas. La base de esa legitimidad es un sistema que puede enunciar leyes y sanciones en ese campo. Eso 
ocurre en el campo de la literatura también en el siglo XIX, cuando se convierte en asunto de hombres de letras independientes y especializados, que crean sus códigos y sus reglas de trabajo y funcionamiento. En términos generales, las instituciones son aparatos de poder; de allí que, si los discursos son producidos por las instituciones, necesariamente en ellos están presentes ciertas relaciones de dominio. Se puede decir que el discurso es el lugar privilegiado del ejercicio del poder porque es a través de él como se constituyen los sujetos y porque es el sujeto donde el poder se ejerce en toda su profundidad. Sin embargo, como ha argumentado ampliamente Foucault, donde hay poder hay resistencia; las relaciones de poder nunca son unívocas sino que en todo discurso se pueden encontrar focos de inestabilidad, puntos de enfrentamiento, de conflicto, de lucha; el discurso, dice Foucault, puede ser instrumento y efecto del poder, pero también obstáculo y punto de partida para una estrategia contraria (Foucault, Michel, Historia de la sexualidad..., 123). ${ }^{4}$

Regresemos a la columna, forma adoptada por estos monumentos. Vamos a postular un nuevo concepto, el de tópico, que nos permite otro acercamiento al discurso. Tópico no simplemente es aquello de lo que se habla, ya se trate de un objeto real o imaginario, sino un objeto de discusión con términos de tratamiento establecidos; en otras palabras, un tópico sería una convención que implica una relación estable entre los individuos que participan en ella. En palabras de Bourdieu, son "lugares en el discurso en los que un grupo entero se encuentra y se reconoce"; así, los tópicos más exitosos son aquellos que logran el estatus de lugares comunes. A partir de esto, podríamos entonces asignar el nombre de discurso al conjunto de tópicos y procedimientos, históricamente conformados, que impulsa y regula la expresión de los individuos que lo habitan, y que les asigna posiciones definidas en el campo de significados que delimita. El tópico "columna" ha sido elaborado desde muchos ángulos y uno, no el menos importante, es en el campo del discurso de la masonería.

Existe una gran cantidad de estudios sobre los aspectos simbólicos de los objetos, tanto los de la vida cotidiana como los utilizados en los

\footnotetext{
${ }^{4}$ De hecho, los textos literarios y los artísticos en general constituyen los lugares en los que la dominación y la resistencia es más encarnizada.
} 
ritos; en ellos siempre se dice que la columna, cuando se usa aisladamente como en el caso de los monumentos del centenario, es un símbolo que pertenece al grupo cósmico del "eje del mundo", junto al árbol, la escalera y el mástil. Su función es conectar el cielo, en tanto morada de las divinidades celestes, con la tierra, morada de los hombres. ${ }^{5}$ En otras tradiciones, como en la masónica, la columna es un símbolo que posee diversos significados: entre otros, es el soporte de la construcción y la unión de sus diferentes niveles; representa, pues, el eje de la construcción y su solidez. Es muy común que aparezcan estas columnas en pares, y entonces simbolizan dos fuerzas opuestas en equilibrio; representan la eterna estabilidad, mientras que la separación entre ellas es el lugar de ingreso a un espacio consagrado. Las dos columnas aluden, en la tradición hebrea, a las construidas por Hiram para el templo de Salomón (Reyes 8,13) a las que llamó Jakim y Boaz. La masonería retoma esta tradición por lo que a la entrada de cada logia siempre se construyen dos columnas que llevan esos mismos nombres. En su interior se edifican otras tres columnas igualmente importantes que representan las tres cualidades capitales: sabiduría, fuerza y belleza, cada una de ellas construida en un estilo arquitectónico dado y se asocian a cada una de las tres máximas autoridades de la logia. La columna jónica representa la sabiduría, está asociada al "Venerable" y sobre ella se asienta la estatua de Minerva; la columna dórica representa la fuerza de espíritu, está asociada al "Primer Vigilante" y lleva una estatua de Hércules; y la columna corintia, que representa la belleza de los actos, asociada al "Segundo Vigilante", sobre la cual se asienta Venus.

Podría parecer arbitrario asociar el tópico "columna" con la tradición masónica en el marco de los monumentos del centenario. Sin embargo, el grado de arbitrariedad se reduce si se piensa que, dentro de los regímenes discursivos en el siglo XIX, el de la masonería era muy importante pues se veía como una institución muy seria que daba capacitación e instrucción a las personas más brillantes de la sociedad, debido entre otras cosas, a la falta de espacios y oportunidades educativas de esa época. Porfirio Díaz, quien ocupó la presidencia del país de 1876

${ }^{5}$ Cfr., entre otros, los de Mircea Eliade, por ejemplo el Tratado de historia de las religiones, Ediciones Cristiandad, Madrid, 1974. 
a 1911, con un breve intermedio de 1880 a 1884, tuvo una instrucción masónica muy fuerte y llegó a ocupar el grado 33, el nivel más alto; la logia que actualmente se considera como una de las más antiguas de Oaxaca, la denominada "Cristo No. 1", fue fundada por Díaz, y el nombre que éste adoptó dentro del rito es el de "pelícano", fuertemente asociado con Cristo. ${ }^{6}$ En relación con Argentina, hay más información: se sabe que el libertador José de San Martín fue masón; también Manuel Belgrano y Vicente López y Planes, el autor del himno nacional de ese país. Entre los miembros de la Convención Nacional Constituyente de 1860, se sabe que eran masones, entre otros: Mariano Fragueiro (su presidente), Domingo F. Sarmiento, José Benjamín Gorostiaga, Nicasio Oroño, José María Gutierrez, Irineo Portela, Salvador María del Carril, José Francisco Seguí, José Mármol, Benjamín Victorica, Wenceslao Paunero, Nicanor Albarellos y el de los actores directos: Bartolomé Mitre, Santiago Derqui y el general Urquiza. Fueron masones también Hilario Ascasubi, Estanislao del Campo y José Hernández, todos reconocidos cultores de la poesía gauchesca. Y, entre los presidentes de la república, se cuenta a Rivadavia, López y Planes, Urquiza, Santiago Derqui, Bartolomé Mitre, Sarmiento, Juárez Celman, Pellegrini, Manuel Quintana, Figueroa Alcorta, R. Sáenz Peña, Victorino de la Plaza, Hipólito Yrigoyen, Agustín P. Justo. ${ }^{7}$

${ }^{6}$ No tenemos ninguna referencia de que Antonio Rivas Mercado, el arquitecto que construyó la columna de la independencia, haya pertenecido a alguna agrupación masónica, aunque es del dominio público que los constructores han estado desde la Edad Media asociados con la masonería; lo que sí se sabe es que una gran cantidad de presidentes de la república, desde el primero de ellos en 1824, fueron masones. Estos presidentes fueron: Guadalupe Victoria, primer presidente (1824-1829); Vicente Guerrero (1830); Guadalupe Gómez Pedraza (1832); Valentín Gómez Farías (vicepresidente 1833); Javier Echeverría (1841); Nicolás Bravo (1842-1843); Benito Juárez (1858-1867 y 1871-1872); Sebastián Lerdo de Tejada (1873-1876); Porfirio Díaz (1876-1880 y 1884-1911); Francisco I. Madero (1911-1912); Álvaro Obregón (1920-1924); Plutarco Elías Calles (1924-1928); Emilio Portes Gil (1928-1930); Pascual Ortiz Rubio (1930-1932); Abelardo L. Rodríguez (1932-1934); Lázaro Cárdenas (1934-1940); Miguel Alemán Valdez (1946-1952); Adolfo López Mateos (1958-1964).

${ }^{7}$ Alcibíades Lappas, La masonería argentina a través de sus hombres, ed. de autor, 1966; un resumen de este libro está en http://www.academiamasonica.org.ar/0102.htm. La lista de los presidentes con sus periodos es la siguiente: Bernardino Rivadavia, primer presidente, entre 1826 y 1827; Vicente López y Planes, presidente provisional tras la renuncia de Rivadavia; Justo José de Urquiza, de 1854 a 1860; Santiago Derqui, entre 
Pero el carácter discursivo del monumento lo podemos identificar de modo más preciso que desde el punto de vista de la masonería, si lo consideramos como uno de los elementos que conforman el patrimonio cultural de un país. Los monumentos del centenario son parte del patrimonio cultural edificado, el cual es uno de los mayores soportes de la memoria colectiva o social; de hecho, monumentos y edificios, así como ciertas áreas urbanas a las cuales se les asigna un valor patrimonial, son puntos de apoyo para la construcción de la memoria social, son como estímulos externos que ayudan a reactivar ciertos rasgos de esta memoria. Un primer acercamiento a la noción de memoria tiende a relacionarlo con la neurología o con la psicología; aquí nos interesa, sin embargo, en su relación con la historia y las ciencias sociales en general. Memoria e historia son nociones muy cercanas ya que tienen una materia prima común: evocan lo mismo, el pasado, pero no se confunden; incluso a veces se consideran como opuestas. De manera intuitiva, vemos la memoria como algo ligado a grupos, entre los que está en primer lugar la familia, que representan posibilidades de aprendizaje y de socialización y que aseguran la continuidad y la identidad de las tradiciones. De allí que sea no solamente individual sino también colectiva pues sus portadores o soportes subjetivos son tanto el individuo como la colectividad social; y puede asumir varias funciones, como la de identificación cultural, de diferenciación e integración, y de control político e ideológico. ${ }^{8}$ En general, se puede considerar como un conjunto de representaciones explícitas y conscientes del pasado que determinan la

1860 y 1861; Bartolomé Mitre, entre 1862 y 1868; Domingo Faustino Sarmiento (gran maestre), entre 1868 y 1874; Miguel Juárez Celman, de 1886 a 1890; Carlos Pellegrini, de 1890 a 1892; Manuel Quintana, entre 1904 y 1906; José Figueroa Alcorta, entre 1906 y 1910; Roque Sáenz Peña, entre 1910 y 1914; Victorino de la Plaza, de 1914 a 1916; Hipólito Yrigoyen, entre 1916 y 1922 y entre 1928 y 1930; Agustín Pedro Justo, entre 1932 y 1938.

${ }^{8}$ Pero, desde el punto de vista ontológico - dice Gilberto Giménez - memoria individual y memoria colectiva son diferentes: la primera es una facultad, mientras que la colectiva "no puede designar una facultad, sino una representación: es el conjunto de las representaciones producidas por los miembros de un grupo a propósito de una memoria supuestamente compartida por todos los miembros de este grupo". ("Cultura, identidad y memoria. Materiales para una sociología de los procesos culturales en las franjas fronterizas". 
definición que nos damos acerca de nosotros mismos y del lugar que ocupamos dentro de un cierto sistema de relaciones; esas representaciones son posibles gracias al orden simbólico y al lenguaje, pero también por la unidad del sujeto consigo mismo.

Desde la década de 1930, Halbwachs hablaba ya de memoria colectiva; consideraba la memoria individual como un fenómeno colectivo, sometido a fluctuaciones y cambios constantes. Estrictamente, dice, la memoria individual no existe pues está relacionada siempre con la del grupo: se recuerda algo por la acción de los otros y la situación; por eso recordar no es revivir sino reconstruir, repensar con imágenes e ideas de hoy la experiencia del pasado. Que la memoria es siempre social lo indica el hecho que el recuerdo sólo emerge en relación con personas, grupos, lugares o palabras; cuando estudia los procesos de memorización colectiva, Halbwachs se refiere a los marcos sociales de la memoria, que son combinaciones de imágenes, ideas o conceptos y representaciones (Los marcos sociales de la memoria).

Aunque los dos registros del pasado, historia y memoria colectiva, se relacionan, el autor piensa que la expresión "memoria histórica" es una contradicción en los términos, puesto que la memoria colectiva es una corriente de pensamiento continuo, que no retiene del pasado sino lo que sigue vivo o es capaz de permanecer en la conciencia del grupo que la mantiene; en ella no hay líneas nítidas de separación, sino límites irregulares e inciertos. Por su parte, la historia responde a una necesidad didáctica de esquematización y está en un nivel distinto de los grupos. La historia se presenta como la memoria universal de los seres humanos, o como el registro del pasado de un grupo, mientras que la existencia de grupos diferentes dentro de las sociedades da lugar a diversas memorias colectivas. Frente al carácter universal de la historia, la memoria colectiva se asienta sobre un grupo limitado en el espacio y en el tiempo; por tanto, cada grupo produce su propio tiempo, diferenciado en parte del tiempo compartido con el resto de la sociedad; no hay un tiempo común a todos los grupos.

Cada individuo es miembro de varios grupos y participa de varios pensamientos sociales; su mirada se sumerge sucesivamente en diversos tiempos colectivos. El individuo lleva siempre en su interior el tiempo social del que no puede desprenderse porque habita ese tiempo. Los 
diversos grupos inmovilizan el tiempo a su manera, o imponen a sus miembros la ilusión de que durante un tiempo, en un mundo que cambia sin cesar, algunas zonas han adquirido una estabilidad y un equilibrio relativos. No sólo es evidente la relación entre la memoria de la persona y la del grupo, sino también entre ésta y la tradición, que es la memoria colectiva de cada sociedad. Por tanto, la memoria, como acto de reconstrucción, nunca es idéntica a alguna imagen del pasado pues en cada generación la memoria entrega a los individuos una realidad que es en parte común y en parte diferente.

Otros autores piensan que negar la memoria individual y reconocer sólo la colectiva como resultado de la interacción social es una postura muy radical y proponen la existencia simultánea de la individual y la social, y dicen que el recuerdo es primero individual, aunque realmente sólo se advierta cuando se destaca del telón de fondo de lo colectivo. Sin embargo, Halbwachs acentúa las funciones positivas de la memoria común, especialmente en su función de refuerzo de la cohesión social por una adhesión afectiva al grupo, y con ello asume que la nación es la forma más acabada de un grupo y la memoria nacional como la forma más completa de la memoria colectiva. La memoria es producto de un aprendizaje por medio de procesos generacionales de socialización, de lo que se llama tradición, es decir, el proceso de comunicación de una generación a la siguiente. Necesita, además, ser continuamente reactivada, de manera periódica para conjurar la amenaza permanente del olvido; éste es el papel de los monumentos celebratorios, de las conmemoraciones y de actividades semejantes, que son algo así como la memoria colectiva en acto.

Otra estudiosa de la sociedad que se ha orientado al estudio de la memoria es Agnes Heller, aunque ella no habla de memoria colectiva sino de una memoria cultural; ésta, dice, "está conformada por objetivaciones que proveen significados de una manera concentrada, significados compartidos por un grupo de personas que los dan por asumidos". Los significados compartidos pueden tener como soportes textos (escritos sagrados, crónicas históricas, literatura), pero también puede estar en monumentos, edificios o estatuas, "señales, símbolos y alegorías igual que depósitos de experiencia, memorabilia erigidos a manera de recordatorios". La memoria cultural está incorporada en prácticas que se re- 
piten regularmente, tales como fiestas, ceremonias, ritos; finalmente, de la misma manera que la memoria individual, la cultural está asociada a lugares donde ha ocurrido algún suceso significativo y único o lugares donde un suceso significativo se repite regularmente (Heller, Agnes, "Memoria cultural, identidad y sociedad civil", 139-143). De manera diferente a la memoria individual, la memoria colectiva o social se construye a lo largo de muchas generaciones de individuos, cada uno de ellos sumergido en relaciones determinadas por estructuras sociales. Es una memoria que representa procesos y estructuras sociales que se transforman; soportes de la memoria tales como los monumentos del centenario de la independencia contribuyen al transporte de la memoria social de una generación a otra.

Si la memoria es un fenómeno construido social e individualmente, también es elemento constituyente del sentimiento de identidad, sea éste también individual o colectivo, por el hecho de ser un factor primordial del sentido de continuidad y coherencia de un individuo o un grupo en la construcción de sí mismo. Según Le Goff, la memoria "es uno de los elementos más importantes de las sociedades desarrolladas y de las sociedades en vías de desarrollo, de las clases dominantes y de las clases dominadas, todas en su lucha por el poder o por la vida, por sobrevivir y por avanzar"; es también "un elemento esencial de lo que hoy se estila llamar la identidad, individual o colectiva, cuya búsqueda es una de las actividades fundamentales de los individuos y de las sociedades de hoy [...]" (El orden de la memoria, 181). La construcción de la memoria social es, por tanto, decisiva para la formación de las identidades colectivas, y esto es parte importante del proceso político. Los movimientos sociales, políticos y culturales, conscientemente o no, operan acciones que dan por resultado la construcción de las identidades colectivas. Por tanto, la cuestión que se plantea es qué papel cumplen los monumentos y, en general, las áreas urbanas con valor patrimonial en la lucha en torno a la construcción de las identidades colectivas.

Así como la memoria es un conjunto de representaciones sobre el pasado, la identidad está también implícita en cualquier representación de nosotros mismos. Memoria e identidad son valores disputados en los conflictos sociales que oponen entre sí a los diversos grupos de una comunidad; de allí que ambas tengan un carácter histórico; la institu- 
ción de la memoria social no es un proceso externo a las prácticas sociales de los agentes sino el resultado de esa acción. Por ello la memoria no es algo fijo en la herencia legada por el pasado, sino que requiere ser continuamente recreada para que pueda dar sentido al orden presente. Memoria e identidad son representaciones, construcciones de la realidad. La memoria, los recuerdos, nos ayudan a comprender el mundo en que vivimos, pero el complejo de relaciones de poder, de género, de clase social, etc., determina lo que debe ser recordado (y lo que debe ser olvidado), por quién y con qué fines. De allí que la memoria colectiva sea al mismo tiempo instrumento y meta del poder y que por tanto haya una lucha por el dominio del recuerdo y de la tradición, por la manipulación de la memoria. ${ }^{9}$

La identidad, también de manera intuitiva, está relacionada con la idea que tenemos acerca de quiénes somos y quiénes son los otros; es decir, con la representación que tenemos de nosotros mismos en relación con los demás. Las comparaciones hechas entre personas hacen descubrir semejanzas y diferencias entre ellas; a partir de las semejanzas encontradas se puede decir que comparten una misma identidad, que hay algo que las distingue de otras personas. Eso que distingue a las personas y a los grupos de otras personas y otros grupos sólo puede ser la cultura: "los materiales con los cuales construimos nuestra identidad para distinguirnos de los demás son siempre materiales culturales" (Giménez, G, "Cultura, identidad y memoria...", 11). La identidad, así como la memoria, puede ser individual si su soporte es el sujeto individual, o colectiva, si su soporte es una colectividad.

Si la identidad tiene por referencia la memoria, entonces la identidad nacional tendrá como referencia la memoria nacional. Esa identidad nacional es una de las múltiples identidades colectivas de las que participamos y tiene relación con los símbolos patrios, con todo lo que refuerza el sentimiento de pertenencia a una nación; allí tienen un importante papel los monumentos, pero también todo eso que acogemos como parte del patrimonio, como áreas urbanas, edificios, puentes, etc. Su preserva-

9 "Lo que sobrevive no es el complejo de lo que ha existido en el pasado, sino una elección realizada ya por las fuerzas que operan en el desenvolverse temporal del mundo y de la humanidad, ya por aquellos que se han ocupado del estudio del pasado y de los tiempos pasados, los historiadores". Jacques Le Goff, El orden de la memoria, 227. 
ción favorece la construcción de la identidad nacional, pero también de identidades regionales y locales, de identidades étnicas y religiosas, y también posibilita la formación de identidades de clases y grupos sociales si se preservan los soportes de la memoria que les corresponden. Por ello, un mismo objeto patrimonial pueda ser una referencia de diferentes identidades. Lo que se buscaría, con respecto a los monumentos, especialmente de los que son los más importantes en la constitución de una identidad nacional, es identificar su papel, en tanto que soportes materiales de la memoria, en el proceso de construcción de la memoria social; y de qué manera su preservación contribuye al proceso de desarrollo. Aquí desembocamos necesariamente con la noción de patrimonio cultural; de manera más precisa, con la de patrimonio edificado.

A partir del siglo XIX, la época de oro de los monumentos que es también el advenimiento de las sociedades modernas, industrializadas y seculares, el patrimonio surge, en el ámbito de los procesos de construcción de los estados-nación, como un artificio creado para fortalecer la pertenencia a un mismo espacio simbólico. En efecto, el patrimonio surge como una invención, como construcción de la modernidad. Al atribuir una trascendencia a determinados símbolos culturales que atestiguan el carácter singular de una determinada comunidad y que confiere una ilusión de permanencia y continuidad en relación al pasado, al mismo tiempo se construye un ideal colectivo para el futuro. En este sentido, el vínculo social básico necesario para la construcción de un sentimiento de pertenencia colectiva, viene a asentarse en el principio de la semejanza cultural que tiene por base una cultura y una historia comunes, que unen e identifican una población (cfr. Ernest Gellner, Nations and Nationalism).

Los modelos de gobierno de los nacientes estados vinieron, de este modo, a dar un nuevo significado a los testimonios del pasado como consecuencia de la necesidad de demostrar lo específico de un pueblo, recurriendo para ello a la búsqueda incesante de sus raíces históricas y culturales en el territorio que sirve de soporte a la nación que, al considerar como patrimonio a los hechos culturales ${ }^{10}$ que mejor demuestren

${ }^{10}$ Por su naturaleza, el patrimonio urbano y arquitectónico, más que cualquier otro, hace posible un proceso de construcción de la memoria social puesto que, como dice Walter Benjamin, la arquitectura es un tipo de obra que se recibe colectivamente, entonces el patrimonio edificado sólo existe en la esfera pública, en contacto con la colecti- 
esta continuidad, esta sensación de permanencia y este sentimiento de pertenencia, en una estrategia de representación nacional idealizada frente a las amenazas de ruptura y desorden provocadas por la heterogeneidad de los nuevos estados. En estos contextos, se producen discursos sobre el pasado que destaquen no sólo la singularidad y grandeza de los hechos culturales convertidos en patrimonio, como es el caso de los monumentos conmemorativos del centenario, sino también sus orígenes remotos y su continuidad a lo largo del tiempo para que promuevan un sentimiento nostálgico en relación al pasado, al mismo tiempo que se presentan como recurso para la construcción del futuro. El patrimonio es, por tanto, una construcción social, un proceso simbólico de legitimación social y cultural, basado en la selección y activación de ciertas edificaciones (no de todas), que permite representar una determinada identidad. Esta representación se procesa a través del rescate de edificios, monumentos, etc., destacados de un conjunto más amplio, que cumplen una finalidad de identificación colectiva por el hecho de ser vehículo de los valores culturales propios de cada sociedad, esto es, objetos seleccionados y construidos por ella en cada momento.

Hablar de patrimonio presupone hablar de identidad en la medida en que ésta puede definirse como una síntesis simbólica de valores que contribuyen al sentimiento de pertenencia e identificación de una colectividad social. Esa capacidad de representación simbólica de las identidades a través de los monumentos ha sido un elemento central en la definición actual del concepto de patrimonio. Si la ciudad moderna del siglo XIX y sus símbolos, especialmente los enraizados en la tradición, dio nacimiento al concepto de monumento histórico, el concepto de patrimonio urbano que hemos adoptado es, de acuerdo con Choay, una consecuencia de los conceptos de monumento y de monumento histórico desarrollados principalmente durante ese siglo.

Una de las acepciones más utilizadas del concepto de patrimonio es aquella que la relaciona con una herencia, con un legado que hemos recibido de nuestros antepasados y que tenemos el deber de transmitir a las generaciones futuras. Así considerada, la herencia cultural contri-

vidad, tiene un carácter que favorece el reconocimiento por parte de grandes grupos lo que favorece las tendencias a la socialización. 
buye a dar cierta estabilidad, permanencia y continuidad de los monumentos y otros hechos culturales que, al mismo tiempo que permiten establecer un puente simbólico entre el pasado, el presente y el futuro, promueven un sentimiento de filiación y pertenencia por parte de los miembros del colectivo social. Sin embargo, esa manera de pensar el patrimonio no permite captar toda la complejidad asociada a ese concepto, puesto que el patrimonio es resultado, en primer lugar, de un proceso de reconocimiento y selección de ciertos hechos urbanos y arquitectónicos que se proyectan y encuentran su justificación en una valoración que remite a su carácter simbólico, esto es, a su necesidad de preservación en virtud del significado que encierra para la colectividad, pero también en su rentabilidad social, o sea, su utilidad y funcionalidad en el plano social y económico. Por tanto, más allá de su relación con el pasado histórico, el patrimonio funciona tanto como herramienta de formación identitaria como instrumento de afirmación y legitimación de grupos sociales. Las áreas urbanas patrimoniales son soportes de la memoria social y, como tales, son importantes para el desarrollo de la sociedad, para la formación del sentido de la historia en la vida cotidiana y para la construcción de las identidades colectivas. Pero esas áreas no se presentan sólo como soportes de la memoria sino también como bienes de valor artístico y cultural. Al aumentar en importancia las actividades económicas relacionadas con la cultura, aumenta la importancia de esa naturaleza artística del patrimonio construido, lo que puede ocasionar intervenciones urbanísticas que menosprecian el carácter de memoria.

Por tanto, las áreas urbanas con valor patrimonial son portadoras de un carácter doble: bienes de carácter artístico-cultural y soportes de la memoria social, con valor histórico. ¿Cómo situarse frente a este carácter doble? Desde un punto de vista económico, la expansión de los servicios, de la actividad económica ligada a la cultura y al turismo es una preocupación. Para esas actividades el valor artístico-cultural es más importante, pero para atender plenamente esos objetivos, se requieren intervenciones, actualización de imagen y otras transformaciones de marketing. El tratamiento del patrimonio como soporte de la memoria impone cambios definidos de la forma arquitectónica y urbanística e impide la instalación de equipamientos urbanos relacionados con el turismo en esas áreas. O sea, el mercado inmobiliario está limitado en 
sus movimientos. También el punto de vista ambiental cada vez es más pertinente en las políticas urbanas. De hecho, la presencia de bienes de valor patrimonial es un factor en la calidad cultural del entorno urbano. Así, el tratamiento del patrimonio como soporte de la memoria es positivo desde el punto de vista ambiental; sin embargo, en la práctica, a veces la política ambiental pasa a segundo término cuando se quiere aumentar la expresividad artístico-cultural, al grado de comprometer su calidad de soporte de la memoria.

Si la sociedad actual trae las marcas de las estructuras sociales que le antecedieron y si estas marcas son potencialmente lo soportes de la memoria, entonces es también por la selección, el análisis y la interpretación de éstos como se construyen la memoria social y el olvido. La memoria colectiva es socialmente construida por la conservación de ciertos soportes convertidos en patrimonio cultural. Esa selección se hace en el ámbito del poder público por medio de un conjunto de acciones, mediadas por la dinámica que involucra la esfera pública, en un contexto político y cultural. En este sentido, el proceso de preservación del patrimonio está condicionado por la acción política. La construcción de la memoria (y, por tanto, del olvido) es objeto de una permanente disputa por parte de los poderes políticos, lo cual ocurre por medio de la decisión qué es lo que debe preservarse. ${ }^{11}$

Con el rescate del pasado por medio de la noción de patrimonio no sólo se busca la recuperación, sino que también se exaltan las actividades y expresiones que puedan convertirse en instrumento para fortalecer la identidad de una comunidad. Pero estas iniciativas asumen, más allá de una vertiente identitaria, un carácter instrumental, pues contribuyen a la legitimación de los poderes instituidos, una vez que la oferta de bienes y actividades culturales responde a los anhelos de una población carente de vínculos de identificación con el territorio, con el pasado y con los demás miembros de la colectividad; se promueve, de este modo, el

${ }^{11}$ Dice Le Goff, "la memoria colectiva ha constituido un hito importante en la lucha por el poder conducida por las fuerzas sociales. Apoderarse de la memoria y del olvido es una de las máximas preocupaciones de las clases, de los grupos, de los individuos que han dominado y dominan las sociedades históricas. Los olvidos, los silencios de la historia, son reveladores de estos mecanismos de manipulación de la memoria colectiva". (134) 
consenso social. En conclusión, aunque pueda ser caracterizado como un proceso de representación cultural basado en el pasado y en las especificidades culturales locales, el patrimonio es una interpretación o recreación de la historia que transmite mitos de origen y de continuidad, que más allá de dotar un grupo de un sentimiento de pertenencia común, contribuye a la legitimación de las instituciones sociales responsables por su activación. Es éste el rasgo discursivo fundamental de los monumentos del centenario.

\section{REFERENCIAS}

ChOAy, Françoise, L'allégorie du patrimoine, Paris, Éditions du Seuil, 1992, 307.

Eliade, Mircea, Tratado de historia de las religiones, Ediciones Cristiandad, Madrid, 1974.

Foucault, Michel, El orden del discurso, Barcelona, Tusquets, 1973.

Foucault, Michel, Historia de la sexualidad. 1. La voluntad de saber, México, Siglo XXI, 1977.

Gellner, Ernest, Nations and nationalism, Ithaca, Cornell University Press, 1983.

GiménEz, Gilberto, “Cultura, identidad y memoria. Materiales para una sociología de los procesos culturales en las franjas fronterizas", Frontera Norte, vol. 21, núm. 41, enero-junio, 2009, 1-32.

HaLbWaChs, Maurice, Los marcos sociales de la memoria [1925], Barcelona, Anthropos, 2004.

Heller, Agnes, "Memoria cultural, identidad y sociedad civil", Indaga. Revista Internacional de Ciencias Socials y Humanas-International Review of Social and Human Sciences, Santa Cruz de Tenerife: Foro de Investigaciones Sociales, 2003.

LAPPAs, Alcibíades, La masonería argentina a través de sus hombres, ed. de autor, 1966.

Le Goff, Jacques, El orden de la memoria, Barcelona, Paidós, 1991.

RIEGL, Aloïs, Le culte moderne des monuments: son essence et sa génesse, Paris, Ed. du Seuil, 1984 [edición en español: El culto moderno a los monumentos. Madrid, Visor, 1987]. 